\title{
Vascular Regenerative Surgery: Promised Land for Tissue Engineers?
}

Review Article

Fortunato $\mathrm{T}^{1,2}$, De Bank $\mathrm{P}^{1}$, Pula $\mathrm{G}^{1 *}$

${ }^{1}$ Department of Pharmacy and Pharmacology, University of Bath, Bath, UK.

${ }_{2}^{2}$ Department of Biomedical Engineering, Technische Universiteit Eindhoven, Eindhoven, Netherlands.

\section{Abstract}

Cardiovascular cell therapy is a promising new field for the development of treatments for cardiovascular diseases, which remain a major cause of mortality around the world. In this review, we highlight the options currently available for the development of specific cell therapy approaches applied to regeneration of cardiac and vascular tissues. Different cell types have attracted a lot of attention and extensive investigations for the treatment of vascular diseases, including embryonic stem cells, mesenchymal stem cells, induced pluripotent stem cells, and endothelial progenitors. The combination of human cells and increasingly safe and physiologically compliant biomaterials is currently offering an unprecedented opportunity to develop effective cell therapy for either major blood vessels or the microvasculature. Efficacy and safety of cell therapy are the challenges for the new generation of regenerative medicine scientists determined to develop new remedies for cardiovascular diseases. Here we present the state of the art in this biomedical field and the options in terms of cell types and biomaterials currently available for cardiovascular cell therapy.

\section{Introduction}

The tissue engineering field has exponentially grown over the last decade and has progressively moved from being exclusively a lab-bench discipline to an emerging part of today's medical care. It has largely evolved from the pre-existing field of biomaterials and consists of the de novo engineering of tissues and organs by combining scaffolds, cells and biological molecules, often drawing cues from the most up-to-date knowledge in developmental biology [1]. Although this field is focused mainly on replacing damaged or lost tissues, it is often somewhat misnamed with the term "regenerative medicine", which has a broader meaning. The latter encompasses research on self-healing - where the emphasis is rather placed on inducing the healing of a target tissue by potentiating the body's own ability to regenerate, through the delivery of biologically active agents, such as nucleic acids or proteins [2]. In addition, tissue engineering has revolutionized the study of human diseases and drug toxicity by supporting the development of three-dimensional in vitro models that can mimic far more realistically tissue-and organ-level structures and functions that are at the root of disease [3]. While our complex immune system performs remarkably well at keeping us safe from disease, its inherent ability to protect us from any foreign agent is also the main reason why the replacement of body tissues and organs is so challenging [4]. Although surgical techniques for transplanting organs have improved tremendously, it is simply not possible to cope with the overwhelming demand for tissues and organs by retrieving them from volunteering donors [5]. Moreover, even in cases where a suitable donor is found and an organ is successfully transplanted, the therapeutic efficacy is only partial and temporary. The most important limitation is that the immune response against the implanted organ requires permanent immunosuppression and thus ensues a lifelong struggle against immune rejection [6]. Hence, tissue engineering aims at overcoming these hurdles by creating new tissues or organs from the cells of the same patient who receives the treatment. This would eliminate the necessity of either finding a compatible donor or using immunosuppressant drugs. There are four important factors that need to be considered in order to successfully engineer a tissue in vitro: an appropriate cell population, a scaffold that can support the cells, the right biomolecules (such as growth factors), and physical and mechanical stimuli to influence the proper development of the construct into the target tissue [7]. Engineering such tissue surrogates at a scale that is clinically relevant brings about a major challenge: the diffusion of oxygen, nutrients and waste products. In the human body, most cells are found within 100-200 $\mu \mathrm{m}$ from the nearest capillary,

*Corresponding Author:

Giordano Pula BSc, PhD, FHEA,

Department of Pharmacy and Pharmacology, University of Bath, Claverton Campus, Bath Spa (UK).

Email: g.pula@bath.ac.uk

Received: April 24, 2017

Accepted: May 30, 2017

Published: June 03, 2017

Citation: Fortunato T, De Bank P, Pula G (2017) Vascular Regenerative Surgery: Promised Land for Tissue Engineers?. Int J Stem Cell Res Transplant. 5(2), 268-276. doi: http://dx.doi.org/10.19070/2328-3548-1700041

Copyright: Pula $\mathbf{G}^{\circ}$ 2017. This is an open-access article distributed under the terms of the Creative Commons Attribution License, which permits unrestricted use, distribution and reproduction in any medium, provided the original author and source are credited. 
which allows for that exchange to happen, and in the lab this can be simulated - or at least compensated for - through the use of perfusion bioreactors [8]. Without its own vascular network, any areas of a construct that are beyond this diffusional limit will not be sufficiently oxygenated, resulting in cell death and, most likely, overall scaffold failure soon after implantation [8]. Therefore, the engineering of artificial blood vessels and capillary networks is not only a major area of interest within the field, but it is also one on which the future success of the whole tissue engineering endeavour depends [9]. Advantages and disadvantages of existing regenerative medicine approaches and the characteristics of ideal vascular grafts are described in Table 1.

\section{Cell Sources for Vascular Tissue Engineering}

The basic strategy for cell-based vascular tissue engineering is described in Figure 1 and consists of 3 fundamental steps: cell isolation, in vitro amplification and implantation. Each tissue engineering strategy faces its own specific challenges and considerations with regards to the choice of cells, but a number of these are common to all, independent of the target tissue. Firstly, it must be feasible to either directly obtain the required number of cells, or devise a method of inducing the proliferation of the starting population to expand these to the necessary numbers, either in vitro or in situ [10]. Next, these cells should be as easy to isolate as possible. In this context, applications based on cells originating from peripheral blood or from relatively non-vital superficial tissues (e.g. skin or adipose tissue) are more likely to be translated to the clinic than those created with cells that require more complicated surgical interventions (e.g. bone marrow or vascular tissue). Cells also need to possess the correct phenotype, or be able to permanently differentiate into it, in order to perform the desired cellular functions such as ECM deposition, cytokine release, etc. Other requirements may include the ability of these cells to integrate in a seamless manner with native cells and tissue, as well as to connect with the existent neural and/or vascular networks. Lastly, cells should be amenable to the chosen delivery method. For example, endothelial cells (ECs) must be delivered using a material that is permissive to their adhesion via surface integrins as their survival is known to be intimately linked to this process [11]. Depending on the nature of the approach and its specifications, a number of different sources of cells can be used for the engineering of vascular tissues. Most patients with vascular disorders are elderly, thus mature vascular cells from these patients are not suitable for tissue engineering. As an example, smooth muscle cells (SMCs) isolated from the walls of blood vessels have been shown to suffer from aging-associated cellular changes, such as decreased proliferation and collagen synthesis [12].

\section{Embryonic stem cells (ESCs)}

Embryonic stem cells are derived from the inner cell mass of the pre-implantation blastocyst and are capable of differentiation into all mature cell types. In addition to their pluripotency, ESCs can also replicate indefinitely while in their undifferentiated state, mainly due to their high telomerase activity. Originally, ES cell lines were derived by co-culture on growth arrested mouse embryonic fibroblasts [13], but more recently they have also been derived under Good Manufacturing Practice (GMP) conditions using human fibroblasts or amnion epithelial cells while avoiding the use of animal products in the culture medium [14, 15], reducing the risk of animal-borne disease transmission and improving

Table 1. Current Vascular Tissue Engineering Approaches.

\begin{tabular}{|c|c|c|}
\hline & Advantages & Disadvantages \\
\hline Allograft & $\begin{array}{l}\text { - Correct morphology and tissue functionality } \\
\text { - Disease cure by introduction of functional cells } \\
\text { from healthy donor } \\
\text { - Standardization and commercialization } \\
\end{array}$ & $\begin{array}{l}\text { - Potential immunogenicity } \\
\text { - Reduced availability }\end{array}$ \\
\hline Autograft & - No immunogenicity and no risk of rejection & $\begin{array}{l}\text { - Not always possible (poor health) } \\
\text { - Unsuitable to treat genetic (or even } \\
\text { epigenetic) diseases }\end{array}$ \\
\hline Xenograft & $\begin{array}{l}\text { - Abundant } \\
\text { - Easily sourced }\end{array}$ & $\begin{array}{l}\text { - Risk of rejection } \\
\text { - Needs to be decellularized } \\
\text { - Risk of zoonotic disease transmission } \\
\text { - Morphological and physiological } \\
\text { differences between species } \\
\end{array}$ \\
\hline $\begin{array}{l}\text { Synthetic } \\
\text { Graft }\end{array}$ & $\begin{array}{l}\text { - Unlimited supply } \\
\text { - Organ-, disease- and individual-specific design } \\
\text { (personalised medicine) } \\
\text { - Specific mechanical and hydrodynamic properties }\end{array}$ & $\begin{array}{l}\text { - Thrombogenicity } \\
\text { - Cytotoxicity } \\
\text { - Poor patency }\end{array}$ \\
\hline $\begin{array}{l}\text { Ideal } \\
\text { Graft }\end{array}$ & $\begin{array}{l}\text { - Complete integration and growth within the host } \\
\text { - Viability and durability post-implant } \\
\text { - Lack of immunogenicity and thrombogenicity }\end{array}$ & $\begin{array}{l}\text { - FDA approval } \\
\text { - Does not yet exist }\end{array}$ \\
\hline
\end{tabular}

Allografts (cells/tissues from different individual of the same species) are the most common approach and offer the advantage of treating genetic conditions but have the disadvantage of being immunogenic. Autografts (obtained from the patient) have the advantage of no immunogenicity but often are limited by the health of the patient and cannot treat genetic diseases. Xenografts (from different species) pose risk of rejection (immunogenicity) and zoonotic disease transmission. Synthetic graft are convenient but displayed so far poor therapeutic efficacy in humans. 
Figure 1. Key Stages in the Tissue Engineering Cycle.

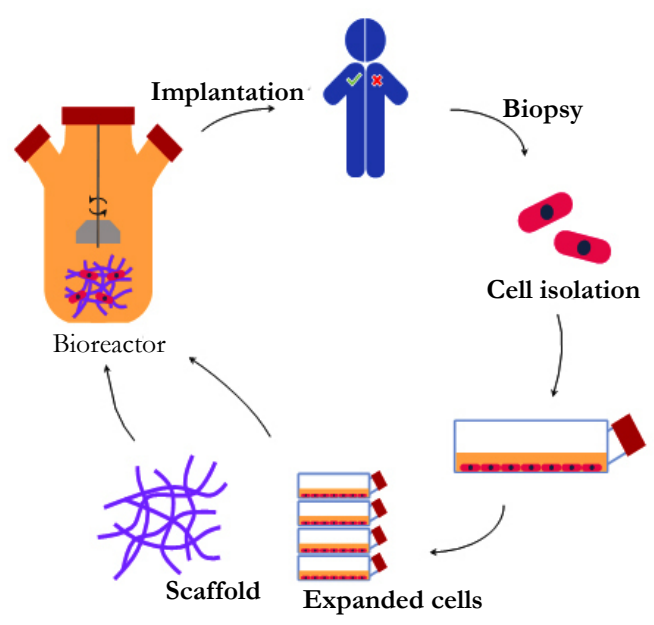

Cells are harvested from a patient, and expanded ex vivo. These are then seeded on an appropriate scaffold and cultured with biochemical and mechanical stimuli. The engineered tissue or organ is then implanted back into the patient to substitute or repair the diseased

organ.

their clinical applicability. Several groups have managed to differentiate human ECSs into ECs, with various degrees of success, and demonstrate their ability to form capillary networks in vivo using murine ischaemic hind limb models $[16,17]$. The differentiation of ESCs has also been guided towards a SMC phenotype [18-20], which could be valuable for the in vitro generation of arterial vessels. Although ESCs constitute a suitable cell source for in vitro disease and drug toxicity modelling and also provide useful insights into the de novo formation of blood vessels (i.e. vasculogenesis) [21], their clinical use is severally hampered by ethical issues that arise from the necessary destruction of human embryos [22]. In addition, another major hurdle has been the potential for teratoma formation as a result of administering patients with pluripotent cells. However, in recent reports of long-term patients, no adverse effects of this nature were shown, despite the immunosuppressant regimen that they were on [23]. Crucially, just like with transplanted organs, ESCs need to be matched to individual patients to avoid immune rejection, thus their future application in the engineering of organs and tissues is dependent on the creation of vast stem cell banks.

\section{Mesenchymal Stem Cells (MSCs)}

Amongst adult stem cells, mesenchymal stem cells (MSCs) exhibit unique characteristics, which make them of great interest for regenerative purposes [24]. MSCs appear to reside in niches in a variety of tissues and can differentiate into numerous lineages to repair damaged tissues, including connective tissue, bone, cartilage or fat [25]. These undifferentiated cells were isolated originally from the bone marrow, but have been since detected and isolated in many other adult tissues such as muscle [26], dental pulp [27], lung [28, 29], saphenous vein [30], liver or adipose tissue [31], thus providing less invasive sources of MSCs for therapy. As with ESCs, these cells have greater in vitro expansion capacity, but are also known for actively secreting trophic factors that promote tissue regeneration and regulate the immune system [32, 33]. MSCs from bone marrow (BM-MSCs) have been extensively investigated in vascular tissue engineering [34], especially to study the interplay between ECM, growth factors and mechanical forces in the differentiation these cells into SMCs during their seed- ing in vascular grafts $[35,36]$. Equally, MSCs from adipose tissue (often called AD-SCs) and muscle have been differentiated into contractile SMCs [37, 38], proliferating on both decellularized veins [39] and artificial scaffolds which had satisfactory mechanical strength [38, 40, 41]. Nevertheless, MSCs appear to be unable to differentiate into ECs in vitro or in situ, a quality necessary for the lumenisation of grafts or the formation of microvascular networks. Researchers have implanted vascular grafts loaded with GFP-labelled BM-MSCs and shown that, despite the beneficial effect of MSCs on the formation of an endothelial lining, this layer had its origin in the host tissue and not from the implanted stem cells [42]. Accordingly, BM-MSCs injected into immunodeficient mice cannot form capillary networks on their own but are able to assist in the stabilisation of networks formed by endothelial progenitor cells (EPCs) through the secretion of a plethora of a pro-angiogenic factors $[43,44]$. This lack of differentiation ability towards an endothelial phenotype may be due to the epigenetic methylation of CD31 and VE-cadherin promoters, as observed in AD-SCs [45]. A hypothesis that has been gaining increasing support suggests that most tissue resident MSCs originate within the perivascular space and not directly from the bone marrow [46], being often labelled as pericyte/adventitial progenitor cells $[47,48]$. As blood vessels are ubiquitously present throughout the body, these MSCs can be rapidly recruited to areas in need of repair in their vicinity [49].

\section{Induced Pluripotent Stem Cells (iPSCs)}

In the last decade, the discovery of a method for reprogramming mature cells into pluripotent stem cells by Shinya Yamanaka's lab [50] has provided a new cell source for tissue engineering that bypasses the immunogenic and ethical issues of other stem cell types. This reprogramming is based on the introduction of four specific genes encoding transcription factors (also known as Yamanaka factors) and prompts adult cells to regress into a stem cell-like state, with comparable self-renewal ability and differentiation potential as ESCs. Similar to the latter, iPSCs can be differentiated into ECs [51], SMCs [52, 53] and pericytes [54]. Zanotelli et al., have shown that ECs obtained this way can self-assemble into capillary networks when cultured in peptide-functionalized poly 
(ethylene glycol) hydrogels in a manner that is representative of the physiological vascular morphogenesis [55]. Additionally, Wang et al., has shown that human iPSC-derived SMCs can be successfully cultured onto macroporouspoly (L-lactide) (PLLA) scaffolds and maintain their phenotype after subcutaneous implantation for at least 2 weeks [56]. In recent years, a new line of research has emerged which is focused on the direct conversion of adult cells into other cell types, including ECs [57, 58] and SMCs [59], while avoiding an intermediate pluripotency stage [60]. This shorter process can be achieved through transdifferentiation, in which lineage-specific factors are ectopically expressed, or through direct reprogramming, that includes an initial partial reprogramming towards the pluripotent state. ECs generated using this partial iPS technology improved neovascularization and blood flow recovery when injected in a hindlimb ischaemia model, and could re-establish the endothelial lining of decellularized vessels in vitro, maintaining their patency [57]. In addition, co-seeding of these vascular grafts with SMCs obtained from partial iPSCs (PiPSCs) led to improved survival following implantation in mice, when compared with cell-free grafts [59]. Besides the potential of the iPSC technology in providing autologous cell sources for regenerative purposes, it is also ideally suited for disease modelling, as the cells generated with these techniques maintain the genetic mutations that were already present in the starting cell population [61].

\section{Endothelial Progenitor Cells (EPCs)}

\section{Early endothelial progenitor cells (eEPCs)}

The first putative kind of circulating progenitor was proposed by Asahara and colleagues in 1997 and was derived by culturing the adherent CD34+ mononuclear cell (MNC) fraction from peripheral blood on to fibronectin coated plates [62]. After 3-7 days, they differentiate and express a number of endothelial/progenitor cell surface markers such as CD133, CD34 and vascular endothelial growth factor receptor (VEGFR-2), and were thus labelled as early endothelial progenitor cells (eEPCs). Although these cells were shown to enhance angiogenesis in a mouse model of hindlimb ischaemia $[62,63]$, their capacity to differentiate into ECs was questioned in subsequent studies implying an haematopoietic origin and showing that these cells did not exhibit a cobblestone morphology typical of endothelial cells or formed vascular networks [64-66]. Accordingly, a later study by Medina et al., determined that eEPCs share a greater extent of their proteome with monocytes than with mature ECs, based on transcriptional and protein profiling of different endothelial progenitors [67]. Moreover, in the same study, caveolae and adherens junctions typical of ECs could not be detected in these cells. It is now fairly well agreed in the field that these short-lived eEPCs contribute to neovascularization by secreting angiogenic growth factors and cytokines, such as VEGF or interleukin 8, rather than forming new blood vessels themselves [68]. Therefore, it appears to be more correct to consider these cells as pro-angiogenic monocytes rather than true endothelial progenitors and, for this reason, they should be used with caution in therapeutic angiogenesis $[67,69]$.

\section{Endothelial Colony Forming Cells (ECFCs)}

Different to eEPCs, the so-called endothelial colony forming cells (ECFCs) are regarded as a true type of endothelial progenitor and show a lack of expression of hematopoietic markers [70]. These cells are also derived from the MNC fraction of blood but are instead obtained as large colonies of adherent endothelial CD45cells with cobblestone morphology after 2-3 weeks of culture on dishes coated with matrix proteins (e.g. collagen) [71]. For this reason, these cells are also referred as late EPCs or outgrowth endothelial cells (OECs) in some research groups, which often generates some confusion in the field [72]. This isolation method was first described by Ingram et al., and is believed to induce the differentiation of a rare population of CD34+/CD133-/CD146+ progenitors into ECs, as these cells can be obtained from both the total MNC fraction as well as from the referred MNC subsets from peripheral blood and cord blood [73, 74]. Although the expression of $\mathrm{CD} 34+$ at their surface points to the bone marrow as their probable source, it is not known with certainty if these progenitors are released directly from this tissue into the bloodstream or if they originate from the wall of bigger vessels, with conflicting reports suggesting both origins $[75,76]$. ECFCs are characterized by the expression of EC markers, such as CD31, VEGFR-2, CD146 and von Willebrand factor and absence of leukocyte markers expression (i.e. CD14 or CD45) [70]. Functionally, ECFCs are known for taking up acetylated low-density lipoprotein (Ac-LDL) and being able to form tubes in vitro on Matrigel as well as capillary networks in vivo [77-79]. Additionally, these cells exhibit a highly proliferative profile and considerable self-renewal capacity, but unlike stem cells, their fate is already committed, thus do not present any risk of teratoma formation [80].

As with iPSCs, ECFCs can be isolated from any person, hence they are ideally suited for autologous therapies aimed at treating ischaemic diseases or for the generation of vascular grafts [81], as well as a tool for studying vascular diseases [82]. However, these applications have also been hampered due their low frequency in blood, with less than 1 colony obtained per $20 \mathrm{~mL}$ [70]. Fortunately, due to the relatively non-invasive nature of blood cell collection, this procedure can be repeated several times to improve the likelihood of successfully isolating these cells. Some researchers have alternatively attempted to increase the number of circulating EPCs prior to blood drawing by promoting their release into the bloodstream with a variety of compounds, such as with the CXCR4 antagonist AMD3100 [83-85]. Of interest to the prospective utilization of these cells for human therapeutic purposes, an animal product-free ECFC isolation and culture method was developed by replacing the foetal bovine serum in the endothelial growth medium (EGM) with pooled human platelet lysate (hPL), getting one step closer to the GMP requirements for clinical use [86]. Additionally, our group has recently demonstrated that ECFCs are capable of forming complete microvascular networks in vitro when encapsulated in a gel-like version of this plateletderived material, suggesting a patient-specific way of delivering these cells for regenerative purposes [87].

In summary, blood constitutes a source of both EPCs and proangiogenic hematopoietic cells, which can be exploited to synergistically promote vascular repair and overall healing of damaged tissues [88]. A schematic of ECFC isolation is shown in Figure 2.

\section{Scaffold-Based Approaches for Vascular Tissue Engineering}

The engineering of vascular tissues is subdivided into two main development areas: microvascular networks and vascular grafts. 
Figure 2. Summary of isolation method for ECFCs from peripheral blood, as first described by Ingram et al., [70].

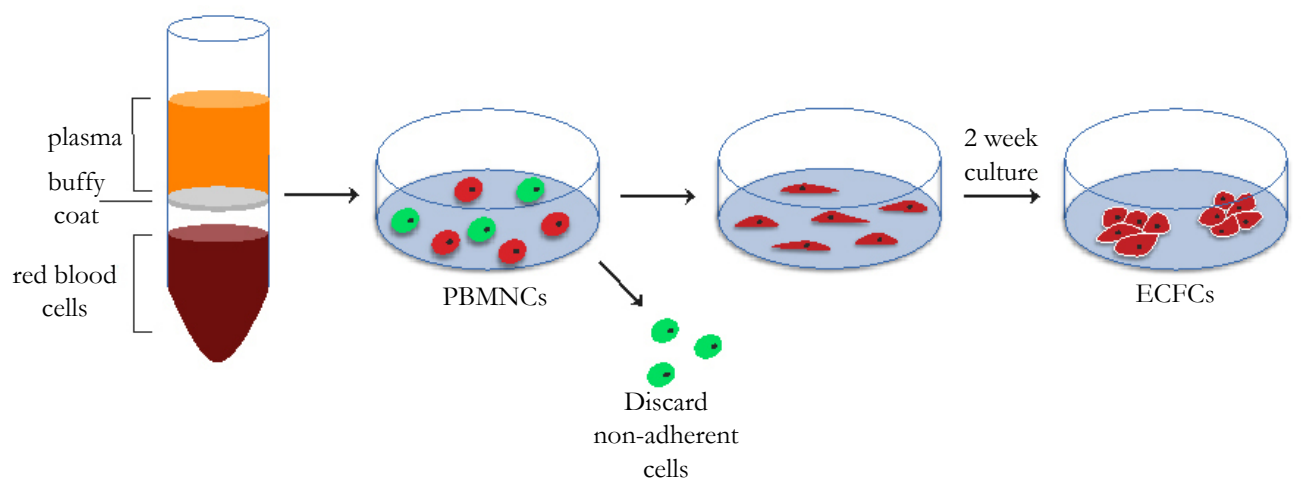

The first involves the creation of capillary networks with the aim of improving blood perfusion and reducing ischaemia in damaged tissues [89]. Some examples are myocardial infarction, where the promotion of local blood supply is necessary to match the considerable oxygen demand of the infarcted myocardium and guarantee its survival [90], and chronic wounds, where insufficient blood vessel network has been shown to hinder full tissue repair [91]. The second comprises the development of replacements for greater calibre vessels to be used in bypass surgeries as an alternative to the use of autologous venous or arterial grafts.

\section{Microvascular Networks}

Hydrogels present several advantages that make them the ideal material type to fulfil these demands. The gelation process through which these hydrophilic networks are formed allows them to be moulded in vitro into any desired shape, while permitting the homogenous dispersion of cells throughout them, or be injected without damaging the targeted and surrounding tissues during delivery [92]. Due their high water content and permeability, the diffusion of oxygen, nutrients as well as secreted molecules is greatly facilitated, which is essential for cell survival. The mechanical profile of these materials also resembles that of most vascularized soft tissues, thus they are able to flex in concert with deformations of host tissue [93]. Their application is not restricted to soft tissues though, as their mouldable nature allows them to be combined with harder materials into bi-phasic scaffolds in order to meet the required stiffness parameters, as for example in the case of engineered bone implants [94]. Hydrogels can be derived from synthetic polymers, such as polyethylene glycol, (PEG), or from natural materials, including silk fibroin, alginate, Matrigel, chitosan, collagen and fibrin, and have been extensively reviewed by others $[92,95,96]$. Depending on their specific origin, natural hydrogels have a number of advantages, including an inherent ability to bind biomolecules (e.g. growth factors), low cost, improved cell adhesion due to inclusion of integrin-binding sequences or susceptibility to cell-mediated proteolytic degradation [97]. However, there are also drawbacks linked to the use of these natural materials, which include issues with purification and batch replicability, immunogenicity or pathogen transmission.

Synthetic hydrogels are advantageous compared to collagen-or fibrin-based hydrogels due to the greater control over material characteristics (including mechanical properties), reduced batchto-batch variability and absence of disease transmission risk [93]. Their superior tunability also allows the design of hydrogels that can react to environmental conditions, changing properties de- pending on factors such as temperature or $\mathrm{pH}$ [98]. Nevertheless, these polymers need to be modified in order to promote cell adhesion or degradation, through coupling of integrin-binding domains (e.g. RGD peptides) and sequences cleavable by matrix metalloproteinase, respectively. In addition, while ECM proteins can naturally bind to most angiogenic GFs, synthetic polymers can only efficiently achieve that following chemical modification [99]. As a consequence, the final cost of synthetic hydrogels for tissue engineering can be considerably higher than that of natural ones. Finally, any new synthetic polymer needs to go through a rigorous process of safety assessment, as many synthetic polymers are potentially cytotoxic [100]. Therefore, synthetic and natural materials can be combined, exploiting the unique properties of each type to obtain a hydrogel with superior overall properties compared to its individual constituents. Such synergistic effect has been recently shown by mixing fibrin and PEG hydrogels in the delivery stem cell-derived ECs in an animal model [101]. The fibrin component allowed the formation of a vascular network and infiltration of supporting pericytes, while PEG increased the stability and longevity of the injectable scaffolds. In a similar manner, Deng et al., showed that the crosslinking of collagen hydrogels with chitosan improves their mechanical properties and increases the in vivo vascular growth into these matrices [102].

\section{Artificial Vascular Grafts}

Synthetic grafts for large-caliber arterial replacement (internal diameter $>6 \mathrm{~mm}$ ) have already proven rather successful in the clinical setting and are usually produced out of nondegradable poly(ethylene terephthalate) $\left(\right.$ Dacron $\left.^{\circledR}\right)$, expanded poly(tetrafluoroethylene) (Teflon ${ }^{\circledR}$ ) or polyurethanes[103, 104]. The lower shear stress near the walls of bigger vessels (e.g. aorta), limits thrombogenicity and leads to satisfactory results with these grafts in terms of patency and durability, despite incomplete endothelialization. However, in the case of small-diameter artery (e.g. coronary artery) grafts made of the same materials, the shear stress is higher resulting in thrombus formation and intimal hyperplasia at the anastomotic site $[105,106]$. Coating of these Teflon-based grafts with heparin has been attempted with a partial improvement in patency rates [107]. Nonetheless, this surface treatment is likely to provide short-lasting benefits for the period immediately following implantation. Because of the limitation of artificial blood vessel implants, most of the vascular interventions are performed using autologous grafts, such as the saphenous vein. In spite of being the current gold standard, the performance of these veins is still not at a satisfactory level, mainly due to the mechanical mismatch. Veins have thinner walls than arteries and 
do not have the mechanical properties to efficiently withstand the higher arterial pressure. This leads to aneurism formation, followed by thickening of the vessel wall (intimal hyperplasia) and accelerated atherosclerosis [108, 109]. Additionally, one third of the patients with peripheral artery disease do not have suitable veins that can be used as autografts and the harvesting of these veins may also result in donor site morbidity [34], thus there is a great demand for an artificial alternative.

There have been two main strategies for engineering vascular grafts: in vitro and in situ. The first aims at generating functional constructs in the laboratory by using cells, scaffolds and bioreactors [110]. In this case, a biodegradable synthetic or naturally derived scaffold is seeded with ECs, SMCs, MSCs or a combination of these. Before being implanted, constructs are cultured in a pulsatile flow bioreactor to mimic the physiological conditions and stimulate cells to remodel the scaffold into the different layers of the blood vessel. Due to its long in vitro culture period, this approach is not suitable for urgent interventions. Nevertheless, a great number of vascular interventions can be planned with sufficient time to fabricate such a kind of graft. The other approach is to engineer a cell-free graft that can selectively recruit cells from the host and allow the remodelling to happen in situ. Because no in vitro incubation is necessary, these grafts can be made available immediately to surgeons as well as at a lower cost. In a recent example of this type of approach, an electrospun vascular graft was modified with recombinant mussel adhesive protein fused to RGD peptides to promote cellular recruitment in situ [111]. This led to enhanced re-endothelialization by mobilized ECs/EPCs and lower graft failure in an in vivo rabbit model.

Independently of the approach followed, lab-engineered grafts are designed with a set of specifications in mind, with the final goal of mimicking the native tissue. The most important mechanical requirements are a burst pressure $\geq 1,700 \mathrm{mmHg}$ (similar to that of saphenous vein) and the ability to resist the cyclic strain of the hemodynamic environment for 30 days in vitro without dilating [112]. It is crucial that the elasticity of the graft is as close as possible to that of the native vessel, as any compliance mismatch leads to turbulence in the blood flow near anastomoses, which in turn increases platelet activation and thrombus formation [113]. Strategies aimed at reducing the thrombogenicity of the surface are often based on the chemical modification the surface with clotting inhibitors or through seeding/capture of ECs/EPCs [114]. In order to be properly integrated over time, the implanted scaffold should also allow the ingrowth of cells from the host, while modulating their cell fate and differentiation to form new tissue. This could be controlled by the microscopic properties, such as porosity, topography, surface chemistry and bioactivity [115] and applies not only to vascular specific cell types but also to immune cells that mediate the inflammatory response to the implant. For example, it has been shown, that the polarization of macrophages towards the tissue remodelling (M2) phenotype on vascular grafts can be promoted by increasing the fibre thickness and porosity of the scaffolds, leading to enhanced ECM deposition by the invading cells [116]. The newly synthetized ECM gradually takes over the mechanical integrity of the graft, whilst the scaffold materials are degraded.

Therefore, the scaffold's degradation rate is another essential parameter to be considered and should be in tune with ECM deposi- tion [117]. In this context, synthetic biodegradable polymers are the first choice for vascular grafts as, compared to natural materials, they provide a much greater control over the degradation rate and other parameters such as porosity, elasticity or microscopic structure [118]. Degradable polyesters, including poly(glycolic acid) (PGA), poly(lactic acid) (PLA), poly(caprolactone) (PCL) and their co-polymers, are the most frequently used in this approach. These polymers are known to be degraded at defined rates, thus are often combined in the same scaffold to achieve the ideal degradation rate for the different graft layers. An interesting example is the work by Lim et al., in which a vascular graft was fabricated using poly(lactide-co-e-caprolactone) (PLCL) and further reinforced with PGA fibres [119]. Following seeding of vascular cells differentiated from autologous BM stem cells, grafts were implanted into the abdominal aorta of dogs and remained patent for the whole duration of the study ( 8 weeks). In summary, scaffolds for vascular grafts should be designed so that they act as an antithrombotic interface with the blood, providing a provisional template for the regeneration of the new arterial vessel, while preventing inflammatory processes that can lead to thrombosis and intimal hyperplasia, especially at the graft anastomoses.

\section{Conclusion}

In summary, the combined advances of vascular cell biology and biomaterial sciences offer a variety of options for the development of cell-based regenerative medicine approaches for cardiovascular biology. In the future, particular attention will need to be dedicated to determine cell sources and biomaterials suitable for the specific medical needs of the pathology and the clinical state targeted. Rigorous and high-powered studies on the efficacy of cell-based or cell/material-based remedies will need to focus on specific cardiovascular conditions and progress swiftly from in vitro to in vivo to clinical settings. Although recent years brought enormous improvements in the characterisation, standardisation and safety of both cells and biomaterials, patient safety will remain the central focus and probably the biggest hurdle for the development of cell therapy approaches applied to cardiovascular regenerative medicine.

\section{References}

[1]. Berthiaume F, Maguire TJ, Yarmush ML (2011) Tissue engineering and regenerative medicine: history, progress, and challenges. Annu Rev Chem Biomol Eng. 2: 403-30.

[2]. Koria P (2012) Delivery of growth factors for tissue regeneration and wound healing. BioDrugs. 26(3): 163-75.

[3]. Benam KH, Dauth S, Hassell B, Herland A, Jain A, et al., (2015) Engineered In Vitro Disease Models. Annu Rev Pathol Mech Dis. 10(1): 195-262.

[4]. Starzl TE, Demetris AJ, Trucco M, Murase N, Ricordi C, et al., (1993) Cell migration and chimerism after whole-organ transplantation: the basis of graft acceptance. Hepatology. 17(6): 1127-52.

[5]. Orlando G, Soker S, Stratta RJ (2013) Organ bioengineering and regeneration as the new Holy Grail for organ transplantation. Ann Surg. 258(2): 221-32.

[6]. Katabathina V, Menias CO, Pickhardt P, Lubner M, Prasad SR (2016) Complications of Immunosuppressive Therapy in Solid Organ Transplantation. Radiol Clin North Am. 54(2): 303-19.

[7]. Hansmann J, Groeber F, Kahlig A, Kleinhans C, Walles H (2013) Bioreactors in tissue engineering - principles, applications and commercial constraints. Biotechnol J. 8(3): 298-307.

[8]. Fiedler T, Belova IV, Murch GE, Poologasundarampillai G, Jones JR, et al., (2014) A comparative study of oxygen diffusion in tissue engineering scaffolds. J Mater Sci Mater Med. 25(11): 2573-8.

[9]. Laschke MW, Menger MD (2016) Prevascularization in tissue engineering: Current concepts and future directions. Biotechnol Adv. 34(2): 112-21. 
[10]. Kumar A, Starly B (2015) Large scale industrialized cell expansion: producing the critical raw material for biofabrication processes. Biofabrication. 7(4): 044103.

[11]. Chavakis E, Dimmeler S (2002) Regulation of endothelial cell survival and apoptosis during angiogenesis. Arterioscler Thromb Vasc Biol. 22(6): 887-93.

[12]. McKee JA, Banik SSR, Boyer MJ, Hamad NM, Lawson JH, et al., (2003) Human arteries engineered in vitro. EMBO Rep. 4(6): 633-8.

[13]. Skottman H, Hovatta O (2006) Culture conditions for human embryonic stem cells. Reproduction. 132(5): 691-8.

[14]. Tannenbaum SE, Tako Turetsky T, Singer O, Aizenman E, Kirshberg S, et al., (2012) Derivation of Xeno-Free and GMP-Grade Human Embryonic Stem Cells - Platforms for Future Clinical Applications. PLoS ONE. 7(6): e35325.

[15]. Lai D, Wang Y, Sun J, Chen Y, Li T, et al., (2015) Derivation and characterization of human embryonic stem cells on human amnion epithelial cells. Sci Rep. 5: 10014

[16]. Levenberg S, Golub JS, Amit M, Itskovitz-Eldor J, Langer R (2002) Endothelial cells derived from human embryonic stem cells. Proc Natl Acad Sci USA. 99(7): 4391-6

[17]. Wang ZZ, Au P, Chen T, Shao Y, Daheron LM, et al., (2007) Endothelial cells derived from human embryonic stem cells form durable blood vessels in vivo. Nat Biotechnol. 25(3): 317-8.

[18]. Huang H, Zhao X, Chen L, Xu C, Yao X, et al., (2006) Differentiation of human embryonic stem cells into smooth muscle cells in adherent monolayer culture. Biochem Biophys Res Commun. 351(2): 321-7.

[19]. Xie C-Q, Zhang J, Villacorta L, Cui T, Huang H, et al., (2007) A highly efficient method to differentiate smooth muscle cells from human embryonic stem cells. Arterioscler Thromb and Vasc Biol. 27(12): e311-2.

[20]. Cheung C, Bernardo AS, Trotter MWB, Pedersen RA, Sinha S (2012) Generation of human vascular smooth muscle subtypes provides insight into embryological origin-dependent disease susceptibility. Nat Biotechnol. 30(2): 165-73.

[21]. Nakagami H, Nakagawa N, Takeya Y, Kashiwagi K, Ishida C, et al., (2006) Model of vasculogenesis from embryonic stem cells for vascular research and regenerative medicine. Hypertension. 48(1): 112-9.

[22]. Vats A, Tolley NS, Bishop AE, Polak JM (2005) Embryonic stem cells and tissue engineering: delivering stem cells to the clinic. J R Soc Med. 98(8): $346-50$.

[23]. Schwartz SD, Regillo CD, Lam BL, Eliott D, Rosenfeld PJ, et al., (2015) Human embryonic stem cell-derived retinal pigment epithelium in patients with age-related macular degeneration and Stargardt's macular dystrophy: follow-up of two open-label phase 1/2 studies. Lancet. 385(9967): 509-16.

[24]. Mo M, Wang S, Zhou Y, Li H, Wu Y (2016) Mesenchymal stem cell subpopulations: phenotype, property and therapeutic potential. Cell Mol Life Sci. 73(17): 3311-21

[25]. Kern S, Eichler H, Stoeve J, Klüter H, Bieback K (2006) Comparative analysis of mesenchymal stem cells from bone marrow, umbilical cord blood, or adipose tissue. Stem Cells. 24(5): 1294-301.

[26]. Young HE, Steele TA, Bray RA, Hudson J, Floyd JA, et al., (2001) Human reserve pluripotent mesenchymal stem cells are present in the connective tissues of skeletal muscle and dermis derived from fetal, adult, and geriatric donors. Anat Rec. 264(1): 51-62.

[27]. Perry BC, Zhou D, Wu X, Yang F-C, Byers MA, et al., (2008) Collection, cryopreservation, and characterization of human dental pulp-derived mesenchymal stem cells for banking and clinical use. Tissue Eng Part C: Methods. 14(2): 149-56.

[28]. Majka SM, Beutz MA, Hagen M, Izzo AA, Voelkel N, et al., (2005) Identification of novel resident pulmonary stem cells: form and function of the lung side population. Stem cells. 23(8): 1073-81.

[29]. Martin J, Helm K, Ruegg P, Varella-Garcia M, Burnham E, et al., (2008) Adult lung side population cells have mesenchymal stem cell potential. $\mathrm{Cy}-$ totherapy. 10(2): 140-51.

[30]. Covas DT, Piccinato CE, Orellana MD, Siufi JLC, Silva WA, et al., (2005) Mesenchymal stem cells can be obtained from the human saphena vein. Exp Cell Res. 309(2): 340-4

[31]. Heidari B, Shirazi A, Akhondi MM, Hassanpour H, Behzadi B, et al., (2013) Comparison of proliferative and multilineage differentiation potential of sheep mesenchymal stem cells derived from bone marrow, liver, and adipose tissue. Avicenna J Med Biotechnol. 5(2): 104-17.

[32]. Squillaro T, Peluso G, Galderisi U (2016) Clinical Trials With Mesenchymal Stem Cells: An Update. Cell Transplant. 25(5): 829-48.

[33]. Castro-Manrreza ME, Montesinos JJ (2015) Immunoregulation by mesenchymal stem cells: biological aspects and clinical applications. J Immunol Res. 2015: 394917.

[34]. Li S, Sengupta D, Chien S (2014) Vascular tissue engineering: from in vitro to in situ. Wiley Interdiscip Rev Syst Biol Med. 6(1): 61-76.
[35]. Kurpinski K, Lam H, Chu J, Wang A, Kim A, et al., (2010) Transforming growth factor-beta and notch signaling mediate stem cell differentiation into smooth muscle cells. Stem Cells. 28(4): 734-42.

[36]. Gong Z, Niklason LE (2008) Small-diameter human vessel wall engineered from bone marrow-derived mesenchymal stem cells (hMSCs). FASEB J. 22(6): 1635-48.

[37]. Rodríguez LV, Alfonso Z, Zhang R, Leung J, Wu B, et al., (2006) Clonogenic multipotent stem cells in human adipose tissue differentiate into functional smooth muscle cells. Proc Natl Acad Sci USA. 103(32): 12167-72.

[38]. Nieponice A, Soletti L, Guan J, Deasy BM, Huard J, et al., (2008) Development of a tissue-engineered vascular graft combining a biodegradable scaffold, muscle-derived stem cells and a rotational vacuum seeding technique. Biomaterials. 29(7): 825-33.

[39]. Harris LJ, Abdollahi H, Zhang P, McIlhenny S, Tulenko TN, et al., (2011) Differentiation of adult stem cells into smooth muscle for vascular tissue engineering. J Surg Res. 168(2): 306-14.

[40]. Heydarkhan-Hagvall S, Schenke-Layland K, Yang JQ, Heydarkhan S, Xu Y, et al., (2008) Human adipose stem cells: a potential cell source for cardiovascular tissue engineering. Cells Tissues Organs . 187(4): 263-74.

[41]. Zambon JP, de Sá Barretto LS, Nakamura ANSE, Duailibi S, Leite K, , et al., (2014) Histological changes induced by Polyglycolic-Acid (PGA) scaffolds seeded with autologous adipose or muscle-derived stem cells when implanted on rabbit bladder. Organogenesis. 10(2): 278-88.

[42]. Mirza A, Hyvelin J-M, Rochefort GY, Lermusiaux P, Antier D, et al., (2008) Undifferentiated mesenchymal stem cells seeded on a vascular prosthesis contribute to the restoration of a physiologic vascular wall. J Vasc Surg. 47(6): 1313-21.

[43]. Melero-Martin JM, De Obaldia ME, Kang S-Y, Khan ZA, Yuan L, et al., (2008) Engineering robust and functional vascular networks in vivo with human adult and cord blood-derived progenitor cells. Circ Res. 103(2): 194-202.

[44]. Lin R-Z, Moreno-Luna R, Zhou B, Pu WT, Melero-Martin JM (2012) Equal modulation of endothelial cell function by four distinct tissue-specific mesenchymal stem cells. Angiogenesis. 15(3): 443-55.

[45]. Boquest AC, Noer A, Sørensen AL, Vekterud K, Collas P (2007) CpG methylation profiles of endothelial cell-specific gene promoter regions in adipose tissue stem cells suggest limited differentiation potential toward the endothelial cell lineage. Stem cells. 25(4): 852-61.

[46]. Corselli M, Crisan M, Murray IR, West CC, Scholes J, et al., (2013) Identification of perivascular mesenchymal stromal/stem cells by flow cytometry. Cytometry A. 83(8): 714-20.

[47]. Spencer HL, Slater SC, Rowlinson J, Morgan T, Culliford LA, et al., (2015) A journey from basic stem cell discovery to clinical application: the case of adventitial progenitor cells. Regen Med. 10(1): 39-47.

[48]. Katare R, Riu F, Mitchell K, Gubernator M, Campagnolo P, et al., (2011) Transplantation of human pericyte progenitor cells improves the repair of infarcted heart through activation of an angiogenic program involving micro-RNA-132. Circ Res. 109(8): 894-906.

[49]. da Silva Meirelles L, Caplan AI, Nardi NB (2008) In search of the in vivo identity of mesenchymal stem cells. Stem Cells. 26(9): 2287-99.

[50]. Takahashi K, Yamanaka S (2006) Induction of pluripotent stem cells from mouse embryonic and adult fibroblast cultures by defined factors. Cell. 126(4): 663-76.

[51]. Li Z, Hu S, Ghosh Z, Han Z, Wu JC (2011) Functional characterization and expression profiling of human induced pluripotent stem cell- and embryonic stem cell-derived endothelial cells. Stem Cells Dev. 20(10): 170110

[52]. Bajpai VK, Mistriotis P, Loh Y-H, Daley GQ, Andreadis ST (2012) Functional vascular smooth muscle cells derived from human induced pluripotent stem cells via mesenchymal stem cell intermediates. Cardiovasc Res. 96(3): 391-400.

[53]. Wang A, Tang Z, Li X, Jiang Y, Tsou DA, Li S (2012) Derivation of smooth muscle cells with neural crest origin from human induced pluripotent stem cells. Cells Tissues Organs . 195(1-2): 5-14.

[54]. Orlova VV, Drabsch Y, Freund C, Petrus-Reurer S, van den Hil FE, et al., (2014) Functionality of endothelial cells and pericytes from human pluripotent stem cells demonstrated in cultured vascular plexus and zebrafish xenografts. Arterioscler Thromb Vasc Biol. 34(1): 177-86.

[55]. Zanotelli MR, Ardalani H, Zhang J, Hou Z, Nguyen EH, et al., (2016) Stable engineered vascular networks from human induced pluripotent stem cell-derived endothelial cells cultured in synthetic hydrogels. Acta Biomater. 35: 32-41.

[56]. Wang Y, Hu J, Jiao J, Liu Z, Zhou Z, et al., (2014) Engineering vascular tissue with functional smooth muscle cells derived from human iPS cells and nanofibrous scaffolds. Biomaterials. 35(32): 8960-9.

[57]. Margariti A, Winkler B, Karamariti E, Zampetaki A, Tsai T-N, et al., (2012) Direct reprogramming of fibroblasts into endothelial cells capable of angio- 
genesis and reendothelialization in tissue-engineered vessels. Proc Natl Acad Sci USA. 109(34): 13793-8.

[58]. Ginsberg M, James D, Ding B-S, Nolan D, Geng F, et al., (2012) Efficient direct reprogramming of mature amniotic cells into endothelial cells by ETS factors and TGF $\beta$ suppression. Cell. 151(3): 559-75.

[59]. Karamariti E, Margariti A, Winkler B, Wang X, Hong X, et al., (2013) Smooth muscle cells differentiated from reprogrammed embryonic lung fibroblasts through DKK3 signaling are potent for tissue engineering of vascular grafts. Circ Res. 112(11): 1433-43.

[60]. Kelaini S, Cochrane A, Margariti A (2014) Direct reprogramming of adult cells: avoiding the pluripotent state. Stem Cells Cloning. 7: 19-29.

[61]. Kim C (2014) Disease modeling and cell based therapy with iPSC: future therapeutic option with fast and safe application. Blood Res. 49(1): 7-14.

[62]. Asahara T, Murohara T, Sullivan A, Silver M, van der Zee R, et al., (1997) Isolation of putative progenitor endothelial cells for angiogenesis. Sci. 275(5302): 964-7.

[63]. Kalka C, Masuda H, Takahashi T, Kalka-Moll WM, Silver M, et al., (2000) Transplantation of ex vivo expanded endothelial progenitor cells for therapeutic neovascularization. Proc Natl Acad Sci USA. 97(7): 3422-7.

[64]. Case J, Mead LE, Bessler WK, Prater D, White HA, et al., (2007) Human CD34+AC133+VEGFR-2+ cells are not endothelial progenitor cells but distinct, primitive hematopoietic progenitors. Exp Hematol. 35(7): 1109-18.

[65]. Yoder MC, Mead LE, Prater D, Krier TR, Mroueh KN, et al., (2007) Redefining endothelial progenitor cells via clonal analysis and hematopoietic stem/progenitor cell principals. Blood. 109(5): 1801-9.

[66]. Rohde E, Malischnik C, Thaler D, Maierhofer T, Linkesch W, et al., (2006) Blood monocytes mimic endothelial progenitor cells. Stem Cells. 24(2): 357-67.

[67]. Medina RJ, O'Neill CL, Sweeney M, Guduric-Fuchs J, Gardiner TA, et al., (2010) Molecular analysis of endothelial progenitor cell (EPC) subtypes reveals two distinct cell populations with different identities. BMC Med Genomics. 3: 18.

[68]. Hur J, Yoon C-H, Kim H-S, Choi J-H, Kang H-J, et al., (2004) Characterization of two types of endothelial progenitor cells and their different contributions to neovasculogenesis. Arterioscler Thromb Vasc Biol. 24(2): 288-93.

[69]. van der Pouw Kraan TCTM, van der Laan AM, Piek JJ, Horrevoets AJG (2012) Surfing the data tsunami, a bioinformatic dissection of the proangiogenic monocyte. Vascul Pharmacol. 56(5-6): 297-305.

[70]. Ingram DA, Mead LE, Tanaka H, Meade V, Fenoglio A, et al., (2004) Identification of a novel hierarchy of endothelial progenitor cells using human peripheral and umbilical cord blood. Blood. 104(9): 2752-60.

[71]. Yoder MC (2009) Defining human endothelial progenitor cells. J Thromb Haemost. 7(1): 49-52.

[72]. Fadini GP, Losordo D, Dimmeler S (2012) Critical reevaluation of endothelial progenitor cell phenotypes for therapeutic and diagnostic use. Circ Res. 110(4): 624-37.

[73]. Timmermans F, Van Hauwermeiren F, De Smedt M, Raedt R, Plasschaert F, et al., (2007) Endothelial outgrowth cells are not derived from CD133+ cells or CD 45+ hematopoietic precursors. Arterioscler Thromb Vasc Biol. 27(7): 1572-9.

[74]. Mund JA, Estes ML, Yoder MC, Ingram DA, Case J (2012) Flow cytometric identification and functional characterization of immature and mature circulating endothelial cells. Arterioscler Thromb Vasc Biol. 32(4): 1045-53.

[75]. Tura O, Skinner EM, Barclay GR, Samuel K, Gallagher RCJ, et al., (2013) Late outgrowth endothelial cells resemble mature endothelial cells and are not derived from bone marrow. Stem Cells. 31(2): 338-48.

[76]. Lin Y, Weisdorf DJ, Solovey A, Hebbel RP (2000) Origins of circulating endothelial cells and endothelial outgrowth from blood. J Clin Invest. 105(1): $71-7$.

[77]. Critser PJ, Yoder MC (2009) Endothelial colony-forming cell role in neoangiogenesis and tissue repair. Curr Opin Organ Transplant. 15(1): 68-72.

[78]. Critser PJ, Kreger ST, Voytik-Harbin SL, Yoder MC (2010) Collagen matrix physical properties modulate endothelial colony forming cell-derived vessels in vivo. Microvasc Res. 80(1): 23-30.

[79]. Mead LE, Prater D, Yoder MC, Ingram DA (2008) Isolation and characterization of endothelial progenitor cells from human blood. Curr Protoc Stem Cell Biol. Chapter 2: Unit2C.1.

[80]. Hirschi KK, Ingram DA, Yoder MC (2008) Assessing identity, phenotype, and fate of endothelial progenitor cells. Arterioscler Thromb Vasc Biol. 28(9): 1584-95

[81]. Medina RJ, O'Neill CL, Humphreys MW, Gardiner TA, Stitt AW (2010) Outgrowth endothelial cells: characterization and their potential for reversing ischemic retinopathy. Invest Ophthalmol Vis Sci. 51(11): 5906-13.

[82]. Medina RJ, O'Neill CL, O'Doherty TM, Wilson SEJ, Stitt AW (2012) Endothelial progenitors as tools to study vascular disease. Stem Cells Int.
2012: 346735.

[83]. Yin Y, Huang L, Zhao X, Fang Y, Yu S, et al., (2007) AMD3100 mobilizes endothelial progenitor cells in mice, but inhibits its biological functions by blocking an autocrine/paracrine regulatory loop of stromal cell derived factor-1 in vitro. J Cardiovasc Pharmacol. 50(1): 61-7.

[84]. Sun J, Xie J, Kang L, Ferro A, Dong L, et al., (2016) Amlodipine Ameliorates Ischemia-Induced Neovascularization in Diabetic Rats through Endothelial Progenitor Cell Mobilization. Biomed Res Int. 2016: 3182764

[85]. Chao T-H, Chen I-C, Lee C-H, Chen J-Y, Tsai W-C, et al., (2016) Cilostazol Enhances Mobilization of Circulating Endothelial Progenitor Cells and Improves Endothelium-Dependent Function in Patients at High Risk of Cardiovascular Disease. Angiol. 67(7): 638-46.

[86]. Reinisch A, Hofmann NA, Obenauf AC, Kashofer K, Rohde E, et al., (2009) Humanized large-scale expanded endothelial colony-forming cells function in vitro and in vivo. Blood. 113(26): 6716-25.

[87]. Fortunato TM, Beltrami C, Emanueli C, De Bank PA, Pula G (2016) Platelet lysate gel and endothelial progenitors stimulate microvascular network formation in vitro: tissue engineering implications. Sci Rep. 6: 25326.

[88]. Yoon C-H, Hur J, Park K-W, Kim J-H, Lee C-S, et al., (2005) Synergistic neovascularization by mixed transplantation of early endothelial progenitor cells and late outgrowth endothelial cells: the role of angiogenic cytokines and matrix metalloproteinases. Circulation. 112(11): 1618-27.

[89]. Rouwkema J, Khademhosseini A (2016) Vascularization and Angiogenesis in Tissue Engineering: Beyond Creating Static Networks. Trends Biotechnol. 34(9): 733-45.

[90]. Ardehali A, Ports TA (1990) Myocardial oxygen supply and demand. Chest. 98(3): 699-705.

[91]. Gordillo GM, Sen CK (2003) Revisiting the essential role of oxygen in wound healing. Am J Surg. 186(3): 259-63.

[92]. Johnson TD, Christman KL (2013) Injectable hydrogel therapies and their delivery strategies for treating myocardial infarction. Expert Opin Drug Deliv. 10(1): 59-72.

[93]. Zhu J, Marchant RE (2011) Design properties of hydrogel tissue-engineering scaffolds. Expert Rev Med Devices. 8(5): 607-26.

[94]. Daculsi G, Uzel AP, Weiss P, Goyenvalle E, Aguado E (2010) Development in injectable multiphasic biomaterials. The performance of microporous biphasic calcium phosphate granules and hydrogels. J Mater Sci Mater Med. 21(3): 855-61.

[95]. El-Sherbiny IM, Yacoub MH (2013) Hydrogel scaffolds for tissue engineering: Progress and challenges. Glob Cardiol Sci Pract. 2013(3): 316-42.

[96]. Rufaihah AJ, Seliktar D (2016) Hydrogels for therapeutic cardiovascular angiogenesis. Adv Drug Deliv Rev. 96: 31-9.

[97]. Munarin F, Petrini P, Bozzini S, Tanzi MC (2012) New perspectives in cel delivery systems for tissue regeneration: natural-derived injectable hydrogels. J Appl Biomater Funct Mater. 10(2): 67-81.

[98]. Klouda L, Perkins KR, Watson BM, Hacker MC, Bryant SJ, et al., (2011) Thermoresponsive, in situ cross-linkable hydrogels based on $\mathrm{N}$-isopropylacrylamide: fabrication, characterization and mesenchymal stem cell encapsulation. Acta Biomater. 7(4): 1460-7.

[99]. Reed S, Wu B (2014) Sustained growth factor delivery in tissue engineering applications. Ann Biomed Eng. 42(7): 1528-36.

[100]. Tian H, Tang Z, Zhuang X, Chen X, Jing X (2012) Biodegradable synthetic polymers: preparation, functionalization and biomedical application. Progress in Polymer Sci. 37(2): 237-280.

[101]. Benavides OM, Brooks AR, Cho SK, Petsche Connell J, Ruano R, et al., (2015) In situ vascularization of injectable fibrin/poly(ethylene glycol) hydrogels by human amniotic fluid-derived stem cells. J Biomed Mater Res. 103(8): 2645-53.

[102]. Deng C, Zhang P, Vulesevic B, Kuraitis D, Li F, et al., (2010) A collagenchitosan hydrogel for endothelial differentiation and angiogenesis. Tissue Eng Part A. 16(10): 3099-109.

[103]. Chlupác J, Filová E, Bacáková L (2009) Blood vessel replacement: 50 years of development and tissue engineering paradigms in vascular surgery. Physiol Res. 58(2): S119-39.

[104]. Spadaccio C, Rainer A, Barbato R, Chello M, Meyns B (2013) The fate of large-diameter Dacron ${ }^{\circledR}$ vascular grafts in surgical practice: are we really satisfied? Int J Cardiol. 168(5): 5028-9.

[105]. Binns RL, Ku DN, Stewart MT, Ansley JP, Coyle KA (1989) Optimal graft diameter: effect of wall shear stress on vascular healing. J Vasc Surg. 10(3): 326-37.

[106].Bennion RS, Williams RA, Stabile BE, Fox MA, Owens ML, et al., (1985) Patency of autogenous saphenous vein versus polytetrafluoroethylene grafts in femoropopliteal bypass for advanced ischemia of the extremity. Surg Gynecol Obstet. 160(3): 239-42.

[107]. Dorrucci V, Griselli F, Petralia G, Spinamano L, Adornetto R (2008) Heparin-bonded expanded polytetrafluoroethylene grafts for infragenicular bypass in patients with critical limb ischemia: 2-year results. J Cardiovasc Surg 
(Torino). 49(2): 145-9.

[108]. Owens CD, Wake N, Conte MS, Gerhard-Herman M, Beckman JA (2009) In vivo human lower extremity saphenous vein bypass grafts manifest flow mediated vasodilation. J Vasc Surg. 50(5): 1063-70.

[109]. Sur S, Sugimoto JT, Agrawal DK (2014) Coronary artery bypass graft: why is the saphenous vein prone to intimal hyperplasia? Can J Physiol Pharmacol. 92(7): 531-45.

[110]. Isenberg BC, Williams C, Tranquillo RT (2006) Small-diameter artificial arteries engineered in vitro. Circ Res. 98(1): 25-35.

[111]. Kang T-Y, Lee JH, Kim BJ, Kang J-A, Hong JM, et al., (2015) In vivo endothelization of tubular vascular grafts through in situ recruitment of endothelial and endothelial progenitor cells by RGD-fused mussel adhesive proteins. Biofabrication. 7(1): 015007.

[112]. Seifu DG, Purnama A, Mequanint K, Mantovani D (2013) Small-diameter vascular tissue engineering. Nat Rev Cardiol. 10(7): 410-21.

[113]. Mitchell SL, Niklason LE (2003) Requirements for growing tissue-engineered vascular grafts. Cardiovasc Pathol. 12(2): 59-64.

[114].de Mel A, Cousins BG, Seifalian AM (2012) Surface modification of bio- materials: a quest for blood compatibility. Int J Biomater. 2012: 707863.

[115]. Fioretta ES, Fledderus JO, Burakowska-Meise EA, Baaijens FPT, Verhaar MC, et al., (2012) Polymer-based scaffold designs for in situ vascular tissue engineering: controlling recruitment and differentiation behavior of endothelial colony forming cells. Macromol Biosci. 12(5): 577-90.

[116]. Wang Z, Cui Y, Wang J, Yang X, Wu Y, et al., (2014) The effect of thick fibers and large pores of electrospun poly ( $\varepsilon$-caprolactone) vascular grafts on macrophage polarization and arterial regeneration. Biomaterials. 35(22): $5700-10$.

[117]. Bouten CVC, Dankers PYW, Driessen-Mol A, Pedron S, Brizard AMA, (2011) Substrates for cardiovascular tissue engineering. Adv Drug Deliv Rev. 63(4-5): 221-41

[118]. Kim BS, Mooney DJ (1998) Development of biocompatible synthetic extracellular matrices for tissue engineering. Trends Biotechnol. 16(5): 224-30.

[119]. Lim SH, Cho S-W, Park J-C, Jeon O, Lim JM, et al., (2008) Tissue-engineered blood vessels with endothelial nitric oxide synthase activity. J Biomed Mater Res Part B Appl Biomater. 85(2): 537-46. 